\title{
Saving the Island in the Sky: the plight of the Mount Mulanje cedar Widdringtonia whytei in Malawi
}

\author{
Julian Bayliss, Steve Makungwa, Joy Hecht, David Nangoma and Carl Bruessow
}

\begin{abstract}
The Endangered Mulanje cedar Widdringtonia whytei, endemic to the Mount Mulanje massif in Malawi, has undergone a drastic decline due to increased fire incidence and illegal logging. Valued for its fine timber, attractive fragrance, and pesticide-resistant sap, the tree has been regarded as highly desirable since its discovery in the late 19th century. Because of its steep slopes and isolated high altitude plateau, Mount Mulanje is also a refuge for a number of other endemic plant species. The first assessment of the Mulanje cedar since 1994 was commissioned by the Mulanje Mountain Conservation Trust to ascertain the species' current extent and status. This study identified an area of 845.3 ha of Mulanje cedar,
\end{abstract}

which represents a loss of 616.7 ha over the previous 15 years. Of the recorded trees $32.27 \%\left(37,242 \mathrm{~m}^{3}\right)$ were dead cedars. Therefore, under current Department of Forestry harvest licensing, there remains in theory sufficient dead cedar to last $>30$ years. At this stage it is imperative that cedar nurseries are established and saplings planted out across the mountain on an annual basis, small cedar clusters are protected to facilitate regeneration, and a strict monitoring programme is followed to prevent the cutting of live cedar.

Keywords Fire, Malawi, Mount Mulanje, Mulanje cedar, Widdringtonia whytei.

\section{Introduction}

The Mulanje cedar was first noted by the Scottish missionary Robert Cleland when he climbed onto the Mulanje plateau in 1888 and 'discovered himself in another world ... with here and there clumps of a tree unknown beyond the mountain' (Jenkins, 1986). This unknown tree was later to become the Mulanje cedar Widdringtonia whytei. The Mulanje cedar was first described by Whyte (1893) and later named by Rendle (1894). Commercial exploitation began in 1898 and continued until 1955, with large areas of forest cleared. The area was gazetted as Mulanje Mountain Forest Reserve in 1927 by the British authorities (when Malawi was known as the Protectorate of Nyasaland), probably more to manage and exploit the plateau's resources than to conserve them (Chapman, 1994). The Mulanje cedar was declared the national tree of Malawi in 1984 by the

Julian Bayliss* (Corresponding author) Wildlife Conservation Society, 2300 Southern Boulevard, Bronx, NY 10460-1090, USA. E-mail jbayliss@wcs.org

Steve Makungwa Department of Forestry and Horticulture, Bunda College, University of Malawi, Lilongwe, Malawi.

Joy Hecht Consultant on Environmental Economics and Policy to the Mulanje Mountain Conservation Trust.

David Nangoma and Carl Bruessow Mulanje Mountain Conservation Trust, PO Box 139, Mulanje, Malawi.

*Also at: Mulanje Mountain Conservation Trust, P.O. Box 139, Mulanje, Malawi.

Received 21 November 2005. Revision requested 17 January 2006. Accepted 24 April 2006 late President Dr Hastings Banda, and has come to symbolize the delicate balance that faces the Mount Mulanje ecosystem. W. whytei is categorized as Endangered on the IUCN Red List (IUCN, 2006). In 2000 the Mulanje Mountain Forest Reserve was designated for inclusion in the World Network of Biosphere Reserves as part of the UNESCO Man and the Biosphere Programme. An application has since been submitted to UNESCO for World Heritage Site status. Such approval will be crucial to the preservation of the mountain's ecosystem, obliging the UN to undertake legal action if the Mulanje ecosystem is threatened.

The genus Widdringtonia contains several species from southern Africa, notably W. cedarbergensis (Cederberg mountains, South Africa), W. schwarzii (Baviaans Kloof Mountains, South Africa), and W. cupressoides (syn. W. nodiflora, found throughout southern Africa; Marsh, 1966). W. whytei was originally thought to be synonymous with $W$. nodiflora, which in turn was thought to be synonymous with W. cupressoides (Marsh, 1966), although this is disputed (Pauw \& Linder, 1997). On Mount Mulanje both the W. nodiflora (multi-stemmed, narrow crowned tree) and W. whytei (taller, wide crowned) forms exist.

There are several threats to the Mount Mulanje ecosystem. The most serious of these are fire, fuelwood collection, illegal logging, unsustainable hunting, invasive species, and the potential threat of bauxite extraction (Bayliss, 2005; Hecht, 2006). Some fires are natural but it is believed that the majority are human made (Chapman, 1995). Hunting fires (to flush out game) are 
widespread, although technically no hunting is allowed inside the Forest Reserve boundaries. Crop-burning fires are also a common occurrence and often spread out of control onto the mountain from outside the Reserve boundaries. Illegal logging of Mulanje cedar is also significant in areas not normally visited by Department of Forestry or Mulanje Mountain Conservation Trust officials (J. Bayliss, pers. obs.).

The spread of invasive species on the plateau is well documented. The most serious is the Mexican pine Pinus patula, originally planted as a nursery crop for the Mulanje cedar and eventually as a plantation crop instead of the Mulanje cedar (Chapman, 1995). It has completely taken over certain areas of the mountain to the detriment of all other native species. Another threat is the aphid Cinara cupressi, originally found on the Mexican cypress Cupressus lusitanica planted c. 80 years ago on Mount Mulanje for timber (Chapman et al., 1991). The aphid attacked the Mulanje cedar and was the cause of death of many trees (Chilima, 1989; Sakai, 1989b). A parasitic wasp Pausia bicolor was released as a biological control for C. cupressi in 1991 (Chilima \& Meke, 1993) but the effectiveness of the programme is unknown and awaits investigation.

About 30 million tons of bauxite exist on Mount Mulanje, mainly on the Lichenya and Chambe plateaus that cover approximately one third of the mountain (Hecht, 2006). If mining does take place it will completely destroy the Mulanje cedar forests in these regions. In December 2005 the Malawi government announced the discussion of open-cast mining with the South African mining company Gondo Resources Management. Currently they are at the prospecting stage although it is thought that mining will start in 2011 following an acceptable Environmental Impact Assessment on behalf of the mining company. It is estimated that the mining will last for at least 25 years (R. Illingworth, pers. comm.).

This study presents the results of the most recent status and distribution survey of the Mulanje cedar. The last survey was in 1994 (Lawrence et al., 1994), during which time Malawi underwent a period of political change following the 30-year rule of President Banda. This time of change had repercussions for the natural environment and there was a decline in the management and protection of the Mulanje cedar. This study assesses the current status of the Mulanje cedar, compares this with the results from previous studies, describes current threats to the tree, and makes conservation recommendations.

\section{Study area}

Known locally as chilumba mu mlengalenga (Island in the Sky) Mount Mulanje rises spectacularly above the plains in southern Malawi and is the highest mountain in tropical southern Africa, rising to $>3,000 \mathrm{~m}$ and covering an area of c. $650 \mathrm{~km}^{2}$ (Fig. 1). Known as a centre of biodiversity, the mountain contains high levels of endemism, with 70 out of 1,330 vascular plant species endemic (Strugnell, 2002). The south-east of the plateau is wetter than the north-west because of the prevailing Mozambique coastal trade winds, creating a range of biomes within the mountain ecosystem. The areas surrounding the mountain are a mosaic of habitat and land use types, with tea estates predominant on the southern and eastern boundaries of the Forest Reserve. The mountain is important for its water catchment value, and gives rise to nine major rivers. On average $2,859 \mathrm{~mm}$ of rain is recorded in the south-east of the plateau at Lichenya and 2,001 $\mathrm{mm}$ on Esperanza Tea Estate at the base of the mountain (R. Illingworth, pers. comm.).

\section{Methods}

Areas of potential cedar clusters were identified using the Mulanje Mountain 1:40,000 topographic map (Department of Surveys, Malawi, 1996), combined with our knowledge of the plateau. Possible cluster boundaries were delineated in consultation with Mulanje Mountain Conservation Trust and Department of Forestry staff. We found this delineation agreed with the results of an independent study (Bouvier, 2006) in which cedar clusters were identified using remote sensing. Predictive models were then used to calculate standing and merchantable volumes of both living and dead cedar.

\section{Mapping}

Each cluster was stratified based on terrain and in each stratum systematic sampling was used to locate plots. An interior baseline was established $100 \mathrm{~m}$ from the edge of a cluster, to account for edge effects. From this point a 500 metre grid was established towards the cluster centre. Circular plots, with a variable radius of 25-60 m to ensure a minimum of 20 trees per plot, were located every $500 \mathrm{~m}$ along each grid line. This gave a total of 33 plots and a sampling intensity of $3.9 \%$ of the total identified cedar coverage of 845.3 ha. The geographic coordinates of each plot centre and of cluster boundaries were recorded with a global positioning system (GPS) to an error of \pm 5-10 m. Boundary coordinates were used in the geographical information system ArcView GIS v. 9 (ESRI, Redlands, USA) to represent cedar clusters as polygons.

\section{Sampling}

The number of plots in each stratum varied depending on the size of the cedar cluster. In each circular plot 20 


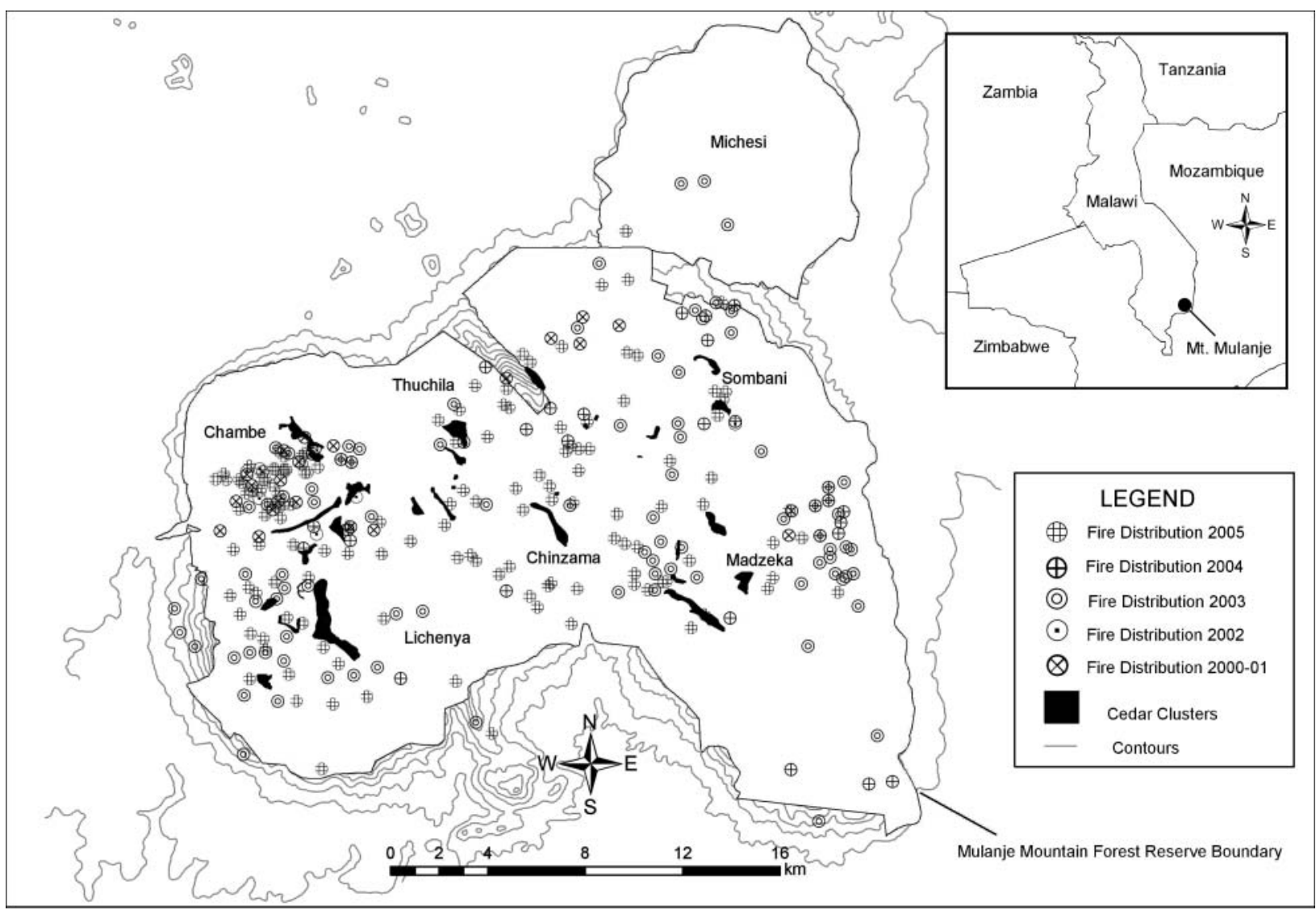

Fig. 1 Mulanje cedar clusters and sites of fires during 2000-2005 on Mount Mulanje. The inset indicates the location of Mount Mulanje in southern Malawi.

Mulanje cedar trees of $\geqslant 5 \mathrm{~cm}$ diameter at breast height (DBH) were identified. The height of the 5th, 10th, and 20th trees from the centre of each circular sampling plot was measured using a hypsometer. Cedars $<5 \mathrm{~cm}$ DBH were recorded as saplings. Dead standing trees within the plot were also measured, to determine standing volume.

\section{Analysis}

The tree assessment models used were developed by Makungwa \& Saramaki (2000) for conifers growing in Malawi.

\section{Standing volume}

The calculation of stem volume used the model $V=$ $10^{* *}\left(-4.318+1.887{ }^{*} \log _{10} D B H+1.021 * \log _{10} h t\right)$, where $V=$ standing volume per tree $\left(\mathrm{m}^{3}\right)$ from stump height $(15 \mathrm{~cm})$ to an upper limit of $5 \mathrm{~cm}$ trunk diameter (including bark), $\log _{10} \mathrm{DBH}$ in $\mathrm{cm}$ includes bark, and $\log _{10} h t=\log _{10}$ of height in $\mathrm{m}$ to an upper limit of $5 \mathrm{~cm}$ trunk diameter. Applying this model to stocking levels, we calculated the total standing volume $\left(\mathrm{m}^{3}\right)$ for each cedar cluster.

\section{Merchantable volume}

Merchantable volumes are commercially viable sizes for timber, measured to certain upper trunk diameters, starting at $13 \mathrm{~cm}$. The calculation of the proportions of merchantable volumes available to upper trunk diameters of 13,20 , and $25 \mathrm{~cm}$ used the model $V_{\mathrm{m}} / V_{5 \mathrm{~cm}}=\beta_{0} *\{[1-$ $\left.\left.\exp \left(\beta_{1}^{*} D B H\right)\right]^{* *} \beta_{2}\right\}$, where $V_{\mathrm{m}}=$ overall merchantable volume to top diameter limit $\left(\mathrm{m}^{3}\right), V_{5 \mathrm{~cm}}=$ volume to $5 \mathrm{~cm}$ top diameter $\left(\mathrm{m}^{3}\right)$, and $D B H$ includes bark.

\section{Results}

We identified a total of 30 cedar clusters in six main regions (Fig. 1). There were marked differences in the percentages of dead and living cedar between regions, and mean density ranged from 41 stems ha ${ }^{-1}$ at Chambe to 131 stems ha ${ }^{-1}$ at Chinzama (Table 1).

Most of the cedars were in the $>55 \mathrm{~cm}$ DBH size class (Table 1), signifying the maturity of the remaining stands. Mean percentages of living and dead trees across the six regions were 67.7 and $32.3 \%$ respectively. Applying the standing volume model to the stocking level statistics (Table 1) gave the total standing volume 
Table 1 Mean density (stems ha ${ }^{-1}$ ) of live and dead cedar (in parentheses) by size class (DBH) and overall, \% live and dead trees, and the total area of identified cedar clusters for the six regions of Mount Mulanje (Fig. 1) as of July 2004.

\begin{tabular}{|c|c|c|c|c|c|c|c|c|c|}
\hline \multirow[b]{2}{*}{ Region } & \multicolumn{6}{|c|}{ Density by size class (DBH in $\mathrm{cm}$ ) } & \multirow[b]{2}{*}{ Overall density } & \multirow[b]{2}{*}{ \% live (dead) } & \multirow[b]{2}{*}{ Area (ha) } \\
\hline & $5-14.9$ & $15-24.9$ & $25-34.9$ & $35-44.9$ & $45-54.9$ & $\geqslant 55$ & & & \\
\hline Chambe & $13(3)$ & $15(2)$ & $1(0)$ & $0(0)$ & $3(0)$ & $4(0)$ & $36(5)$ & $87.8(12.2)$ & 133.5 \\
\hline Chinzama & $19(0)$ & $7(0)$ & $10(11)$ & $16(3)$ & $15(7)$ & $10(33)$ & $77(54)$ & $58.8(41.2)$ & 60.1 \\
\hline Lichenya & $1(1)$ & $7(7)$ & $10(11)$ & $16(9)$ & $7(5)$ & $15(2)$ & $56(35)$ & $61.5(38.5)$ & 256.1 \\
\hline Madzeka & $0(0)$ & $0(0)$ & $0(10)$ & $2(8)$ & $2(4)$ & $45(17)$ & $49(39)$ & $55.7(44.3)$ & 163.4 \\
\hline Sombani & $15(0)$ & $14(3)$ & $28(3)$ & $13(16)$ & $13(5)$ & $16(0)$ & $99(27)$ & $78.6(21.4)$ & 53.6 \\
\hline Thuchila & $7(1)$ & $3(8)$ & $7(12)$ & $6(6)$ & $10(4)$ & $24(3)$ & $57(34)$ & $62.6(37.4)$ & 178.6 \\
\hline Total & & & & & & & & & 845.3 \\
\hline Mean $\pm S D$ & & & & & & & & $\begin{array}{c}67.7 \pm 12.4 \\
(32.3 \pm 12.4)\end{array}$ & \\
\hline
\end{tabular}

Table 2 Total standing volume $\left(\mathrm{m}^{3}\right)$ of cedar, and of living and dead cedar separately, for the six regions of Mount Mulanje (Fig. 1) as of July 2004.

\begin{tabular}{lccc}
\hline Region & Total $\left(\mathrm{m}^{3}\right)$ & Live $\left(\mathrm{m}^{3}\right)$ & Dead $\left(\mathrm{m}^{3}\right)$ \\
\hline Chambe & 7,232 & 5,407 & 1,825 \\
Chinzama & 5,653 & 3,819 & 1,834 \\
Lichenya & 43,753 & 27,702 & 16,051 \\
Madzeka & 20,482 & 14,434 & 6,048 \\
Sombani & 9,348 & 6,764 & 2,584 \\
Thuchila & 28,933 & 20,033 & 8,900 \\
Total & 115,401 & 78,159 & 37,242 \\
\hline
\end{tabular}

Table 3 Values for regression coefficients used in the merchantable volumes model.

\begin{tabular}{lllrl}
\hline & $\beta_{0}$ & $\beta_{1}$ & \multicolumn{1}{c}{$\beta_{2}$} & \multicolumn{1}{l}{$\mathrm{R}^{2}$} \\
\hline $\mathrm{V}_{13 \mathrm{~cm}}$ & 0.942 & -0.288 & 53.358 & 0.920 \\
$\mathrm{~V}_{20 \mathrm{~cm}}$ & 0.855 & -0.248 & 202.375 & 0.930 \\
$\mathrm{~V}_{25 \mathrm{~cm}}$ & 0.827 & -0.222 & 399.521 & 0.950 \\
\hline
\end{tabular}

and volumes of living and dead cedar for each of the six regions (Table 2). There was a total standing volume of Mulanje cedar of $115,401 \mathrm{~m}^{3}$. This result represents a relatively large amount of available dead standing timber.
The regression coefficients for the proportions of merchantable volumes of trees with upper trunk diameters of 13,20 , and $25 \mathrm{~cm}$ are given in Table 3 . Using these coefficients in the merchantable volume model gave merchantable volumes of dead standing cedar of $31,239 \mathrm{~m}^{3}(13 \mathrm{~cm}), 26,922 \mathrm{~m}^{3}(20 \mathrm{~cm})$ and $22,082 \mathrm{~m}^{3}(25 \mathrm{~cm})$.

\section{Discussion}

Several previous assessments of cedar have been undertaken on Mount Mulanje (Edwards, 1982; Sakai, 1989a,b; Lawrence et al., 1994; Table 4). Although these studies differed in the methodologies employed, making direct comparison difficult, they did assess the available cedar stands on the main Mulanje massif. All the studies noted a low natural regeneration of cedars and relatively high mortality rates (currently $32.6 \%$ of standing cedar is dead). Sakai (1989a) calculated an area of Mulanje cedar equivalent to 1,462 ha, whereas we calculated an area of 845.3 ha, representing a decrease of 616.7 ha in 15 years (a $2.8 \%$ loss per year). Based on our volume estimates, this represents an annual loss of $5,611 \mathrm{~m}^{3}$, or approximately 15 cedar trees per day. At this rate, assuming a $1 \%$ natural growth rate (Hecht, 2006), all the accessible cedar will disappear within the next 8 years. A recent

Table 4 Number of survey plots used, total area of Mulanje cedar (if available), and percentage living and dead trees from this study in 2004 and the three earlier studies. The 1982 study presented data for the Thuchila and Lichenya regions only, and separately, and therefore this data is also provided for 2004 .

\begin{tabular}{|c|c|c|c|c|c|}
\hline Year & No. of plots & Total area (ha) & $\%$ living & $\%$ dead & Reference \\
\hline 1982 & 18 & & $\begin{array}{l}76.9 \text { (Thuchila) } \\
84.4 \text { (Lichenya) }\end{array}$ & $\begin{array}{l}23.2 \text { (Thuchila) } \\
15.6 \text { (Lichenya) }\end{array}$ & Edwards (1982) \\
\hline 1989 & 48 & 1,462 & & & Sakai (1989b) \\
\hline 1994 & 21 & & 61 & 39 & $\begin{array}{l}\text { Lawrence et al. } \\
(1994)\end{array}$ \\
\hline 2004 & 33 & 845.3 & $\begin{array}{l}67.7 \\
62.6 \text { (Thuchila) } \\
61.5 \text { (Lichenya) }\end{array}$ & $\begin{array}{l}32.3 \\
37.4 \text { (Thuchila) } \\
38.5 \text { (Lichenya) }\end{array}$ & This study \\
\hline
\end{tabular}


remote sensing analysis of land use change on the mountain found that Afromontane and mid altitude forest declined from 9,292 to 7,928 ha between 1973 and 2002 , an annual decline of $0.5 \%$ per year (Bouvier, 2006). The Mulanje cedar therefore appears to be declining at a greater rate than the forest overall. Comparisons for the Thuchila and Lichenya regions separately between 1982 (Edwards, 1982) and 2004 suggests that there has been a decrease in survival rates (Table 4).

The Malawi Department of Forestry currently licenses only the utilization of dead Mulanje cedar trees. The number of licenses issued per season, while reviewed annually, averages 20 pit sawyers. The mean yield (volume) of an individual pit sawyer in one cedar cutting season on Mount Mulanje has been estimated to be $20 \mathrm{~m}^{3}$ (J. Juwawo, pers. comm.), thereby harvesting an annual average of $400 \mathrm{~m}^{3}$. Based on this we consider that the volume of accessible dead cedar trees currently standing on the mountain $\left(37,242 \mathrm{~m}^{3}\right.$ at a top diameter of $5 \mathrm{~cm}$; Table 2) could, at least in theory, last for 30 years if utilized at the current rate with proper supervision and monitoring.

However, these figures do not take into account illegal logging activities. In 2005 Mulanje Mountain Conservation Trust and the Department of Forestry confiscated $>500$ cedar planks, or $28.5 \mathrm{~m}^{3}$ (assuming 1 plank equals $0.057 \mathrm{~m}^{3}$ based on an average size of $5.4 \times$ $0.21 \times 0.05 \mathrm{~m}$ ) in a single raid. This equates to $>33$ trees (assuming 15 planks per tree), with the majority of planks cut from live trees (the sap was still fresh). However, the resources of these two organizations to combat illegal logging are limited and it is likely that many more illegal activities, including hunting and encroachment, are going undetected.

The greatest threat to the Mulanje cedar is, however, probably uncontrolled fire. As part of a monitoring programme developed on behalf of Mulanje Mountain Conservation Trust by the Wildlife Conservation Society (Bayliss, 2005), fire is monitored through the use of a rapid alert system, the Web Fire Mapper (Justice et al., 2002). This relies on fires being detected through satellite supervision, with alerts sent detailing the exact location of each fire (Fig. 1). Thus the incidence and distribution of fires can be monitored and investigated for causality.

Mulanje cedar has a high commercial value. The wood is rot-proof and the sap is toxic, and therefore termites do not attack it, a great advantage in tropical Africa. Whilst these qualities have fuelled the exploitation of the tree they could also help save it through a programme of sustainable resource utilization if strict guidelines and monitoring could be put in place. Based on the results of this survey we make the following conservation recommendations:
- Although there is a system in place to detect the occurrence of fire, there are no means to fight any fires. The Department of Forestry, supported by Mulanje Mountain Conservation Trust, need to create a team specifically for fire fighting.

- A reforestation programme is required for all areas that were historically cedar forests. This could be achieved through establishment of more cedar nurseries to support the current three small nurseries. There is the potential for at least nine, situated at each of the mountain huts.

- Research is required into the germination and propagation of the Mulanje cedar. It is known to be easy to germinate (Chapman, 1995) but difficult to establish thereafter.

- The Mulanje cedar is still being attacked by the aphid Cinara cupressi, a phenomenon that was initially studied in 1985 (Chilima, 1989). Further investigation of the scale of this problem could be undertaken by the Forestry Research Institute of Malawi.

- Currently much live cedar is harvested under the Department of Forestry logging licenses (J. Bayliss, pers. obs.). The utilization of only dead Mulanje cedar needs to be strictly enforced under a workable monitoring system. This is the responsibility of the Department of Forestry and Mulanje Mountain Conservation Trust.

- All exotic organisms need to be eradicated from the Mulanje massif. Notably this includes the Mexican pine Pinus patula, the aphid Cinara cupressi, the Himalayan raspberry Rubus ellipticus, and bracken Pteridium aquilinum.

- Planned open cast mining for bauxite would destroy approximately one third of the plateau and its flora and fauna. It is essential that the Environmental Impact Assessment undertaken by the mining company is critically examined by a panel of international experts.

Mount Mulanje is currently threatened by fire, bauxite extraction, illegal and unsustainable logging of the Mulanje cedar forests, and the unsustainable fuelwood collection that threatens the lowland woodlands. It is also an area with high levels of biodiversity and endemism, of immense natural beauty, and with landmark status as the second highest mountain in southern Africa. The plateau should be given World Heritage Site status and afforded an appropriate level of protection to ensure its resources are secured for future generations.

\section{Acknowledgements}

Thanks are especially due to Jim Chapman for his tireless efforts to conserve Mount Mulanje over the last 
50 years, and for his comments on this paper. Thanks are also due to Alison Strugnell for her work in the production of the vascular plant checklist, to Tim Davenport and Graeme Patterson of the Wildlife Conservation Society, to all at the Kew Millennium Seed Bank Project, notably Paul Smith, and to past forestry officers, especially Geoffrey Ayres, and researcher Isao Sakai. Thanks are also due to the senior forest assistant, Mr J.T. Juwawo, to his continuing work on the mountain in light of difficult circumstances.

\section{References}

Bayliss, J. (2005) An Ecological Monitoring Programme for Mount Mulanje Forest Reserve. Unpublished Report for the Wildlife Conservation Society/Mulanje Mountain Conservation Trust, Mulanje, Malawi.

Bouvier, I. (2006) Mount Mulanje Land Cover Time Series Analysis. STTA Draft Report. Community Partnerships for Sustainable Resource Management in Malawi, COMPASS, Blantyre, Malawi.

Chapman, J.D. (1994) Afromontane regional centre of endemism: CPD Site AF64, Mount Mulanje, Malawi. In Centres of Plant Diversity, Volume 1: Europe, Africa, South-west Asia and the Western Indian Ocean Islands (eds S.D. Davies, H.V. Heywood \& A.C. Hamilton), pp. 240-247. IUCN/WWF, Cambridge, UK.

Chapman, J.D. (1995) The Mulanje Cedar. Malawi's National Tree. The Society of Malawi, Blantyre, Malawi.

Chapman, J.D., Seyani, J.H. \& Chikuni, A.C. (1991) The Mulanje Mountain in Malawi - a world heritage resource worth conserving. Paper presented at the XIIIth AETFAT Congress, Zomba, Malawi.

Chilima, C.Z. (1989) Cinara cupressi: A Pest of Mulanje Cedar and Cypress Trees in Malawi. Report no. 89009, Forestry Research Institute of Malawi, Zomba, Malawi.

Chilima, C.Z. \& Meke, G.S. (1993) Biological Control of Conifer Aphids in Malawi: An Update on Developments since 1991. Forestry Research Institute of Malawi, Zomba, Malawi.

Edwards, I. (1982) A Report on Mulanje Cedar (Widdringtonia nodiflora) Resources on Mulanje Mountain. Report no. 82035 Forestry Research Institute of Malawi, Zomba, Malawi.

Gelfand, M. (1964) Lakeside Pioneers: Socio-medical Study of Nyasaland (1875-1920). Blackwell, Oxford, UK.

Hecht, J. (2006) Valuing Mount Mulanje: Work in Progress. Report for COMPASS II \& the Mulanje Mountain Conservation Trust, Blantyre \& Mulanje, Malawi.

IUCN (2006) 2006 IUCN Red List of Threatened Species. IUCN, Gland, Switzerland [http://www.redlist.org, accessed 10 January 2006].

Jenkins, P.J. (1986) Mission accomplished. Journal of the Society of Malawi, 39, 17-25.

Justice, C.O., Giglio, L., Korontzi, S., Owens, J., Morisette, J.T., Roy, D., Descloitres, J., Alleaume, S., Petitcolin, F. \&
Kaufman, Y. (2002) The MODIS fire products. Remote Sensing of Environment, 83, 244-262.

Lawrence, M.J., Oshino, A. \& Chinguwo, C. (1994) Mulanje Cedar (Widdringtonia cupressoides Endlicher) Inventory. Report no. 94010, Forestry Research Institute of Malawi, Zomba, Malawi.

Makungwa, S. \& Saramaki, J. (2000) Growth and Yield Models for Pinus and Eucalyptus species in Malawi. Report no. 01010, Forestry Research Institute of Malawi, Zomba, Malawi.

Marsh, J.A. (1966) Cupressaceae. In Flora of Southern Africa, Vol. 1 (eds L.E. Codd, B. de Winter \& H.B. Rhycroft), pp. 43-48. Government Printer, Pretoria, South Africa.

Pauw, C.A. \& Linder, H.P. (1997) Tropical African cedars (Widdringtonia, Cupressaceae): systematics, ecology and conservation status. Botanical Journal of Linnean Society, 123, 297-319.

Rendle, A.B. (1894) The plants of Milanji, Nyasaland, collected by Mr. Alexander Whyte: Gymnospermae. Transactions of the Linnean Society, London, Botany, 4, 60-62.

Sakai, I. (1989a) Preliminary Study on the Growth of Natural Mulanje Cedar on Mulanje Mountain. Report no. 89008, Forestry Research Institute of Malawi, Zomba, Malawi.

Sakai, I. (1989b) A Report on the Mulanje Cedar Resources and the Present Crisis. Forestry Research Record no. 65, Forestry Research Institute of Malawi, Zomba, Malawi.

Strugnell, A.M. (2002) Endemics of Mount Mulanje - the endemic spermatophytes of Mount Mulanje, Malawi. Systematics and Geography of Plants, 72, 11-26.

Whyte, A. (1893) The Plants of Milanji, Nyasaland. Transactions of the Linnean Society of London Series 2, Botany, IV, 1-67.

\section{Biographical sketches}

Julian Bayliss is a conservation biologist and landscape ecologist. He is currently working with the Mulanje Mountain Conservation Trust (http:/ / www.mountmulanje. org.mw) and the Royal Botanical Gardens Kew, London, UK, coordinating a Darwin Initiative project in Mozambique.

Steve Makungwa is a lecturer in Forestry Inventory and Mensuration at the University of Malawi. He specializes in forestry assessment techniques in Malawi.

Joy Hecht is a freelance consultant on environmental economics and policy, working in many regions of the developing world.

David Nangoma is the Biodiversity Officer for the Mulanje Mountain Conservation Trust and currently coordinates the Ecological Monitoring Programme for Mount Mulanje.

Carl Bruessow is the Executive Director of the Mulanje Mountain Conservation Trust. His interests lie in project development and he has many years of experience in protected area management in Malawi. 